\title{
PERCEPÇÕES E REAÇÕES DE PROFESSORES E ALUNOS FRENTE ÀS EMOÇÕES NA AULA DE MATEMÁTICA
}

\author{
PERCEPCIONES Y REACCIONES DE PROFESORES Y ALUMNOS \\ FRENTE A LAS EMOCIONES EN LA CLASE DE MATEMÁTICAS
}

Tânia Cristina Rocha Silva Gusmão

Universidade Estadual do Sudoeste da Bahia - UESB

Mariluce Cidade França Doria

Universidade Estadual do Sudoeste da Bahia - UESB

José Eduardo Rocha Silva

Universidade Estadual do Sudoeste da Bahia - UESB

\begin{abstract}
Resumo
O presente artigo objetiva investigar as percepções e reações de professores e alunos frente às emoções na aula de matemática, bem como fazer o confronto de suas percepções e reações. Participaram desta pesquisa nove professores de matemática do ensino fundamental e médio e seus respectivos alunos de três escolas particulares e uma pública do município de Vitória da Conquista - Bahia, Brasil. Dentro de uma abordagem qualitativa os dados foram analisados à luz do referencial teórico sobre emoções. Professores e alunos não somente revelaram suas percepções e reações, como também, o que provocaram as emoções e quais foram as mais facilmente reconhecidas.
\end{abstract}

Palavras-Chave: Educação Matemática. Ensino-aprendizagem. relação professor-aluno. Emoções.

\section{Resumen}

Este artículo tiene como objetivo investigar las percepciones y reacciones de profesores y alumnos hacia las emociones en la clase de matemáticas, así como comparar sus percepciones y reacciones. Nueve profesores de matemáticas de primaria y secundaria y sus respectivos alumnos de tres escuelas privadas y una escuela pública en la ciudad de Vitória da Conquista - 
Bahía, Brasil, participaron en esta investigación. Dentro de un enfoque cualitativo, los datos se analizaron a la luz del marco teórico sobre las emociones. Los professores y los alumnos no solo revelaron sus percepciones y reacciones, sino también qué provocó las emociones y cuáles fueron las más fáciles de reconocer.

Palabras clave: Educación matemática. Enseñanza-aprendizaje. Relación profesor-alumno. Emociones.

\section{INTRODUÇÃO}

Na sociedade, ainda há uma herança cultural questionável, influência do positivismo, que concebe algumas emoções como danosas para as nossas vidas. Não vamos negar que, sob certas circunstâncias, algumas emoções podem influenciar negativamente os processos de raciocínio. Entretanto, parte dessa influência pode ser decorrente dos conselhos com que fomos educados, como: "Mantenha a cabeça fria, mantenha as emoções afastadas! Não deixe que as paixões interfiram no bom juízo" (DAMÁSIO, 1996). Por conseguinte, a escola, por vezes, cumpre um papel de (re)alimentar esta visão que a sociedade carrega sobre as emoções.

Como se não bastassem os mitos que povoam as emoções, há ainda um desconhecimento de como funcionam os processos emocionais, qual a sua natureza e como se manifestam, e que tem levado professores e alunos a apresentarem dificuldades no trato com as emoções na sala de aula.

Pesquisadores vêm mostrando que "o bicho não é tão feio quanto se pinta". Damásio (1996) afirma que as emoções são necessárias para a sobrevivência do organismo e para os processos racionais. Almeida (1999) ressalta que, apesar do desconhecimento que se tem da reciprocidade entre os processos afetivos/emocionas e os processos racionais, existe entre ambos uma integração que permite uma mútua nutrição.

$\mathrm{Na}$ tentativa de contribuir e ampliar o leque de discussões sobre a influência das emoções na aprendizagem de matemática, esta pesquisa tem por objetivos, numa primeira etapa, investigar a percepção e reação de professores e alunos de matemática frente às 


\section{PERCEPÇÕES E REAÇÕES DE PROFESSORES E ALUNOS FRENTE Às EMOÇÕES NA AULA DE MATEMÁTICA}

emoções na sala de aula e, numa segunda, fazer um confronto entre essas percepções e reações.

E para responder aos objetivos propostos, discorreremos sobre a natureza, função e processos expressivos das emoções, considerando o contexto sociocultural e cognitivo nelas implicado e, também, as contribuições de alguns pesquisadores no campo da Educação Matemática, a exemplo de McLeod (1988, 1989, 1991), Lopes (1997), Chacón (2000), Gusmão (2000, 2009) e Amorim (2017).

\section{Um pouco sobre o estudo das emoções}

Alguns autores são de opinião que o termo emoção é passível de definição e, cada qual, a partir de seu referencial teórico, tenta defini-la. Nesse estudo entendermos emoção como:

\footnotetext{
Entre todos os sentimentos emanados do aluno no trato com a matemática, aquele que se mostrar mais ativo, e que na maioria das vezes se manifesta no seu maior grau sentimental (...) Numa só palavra, o sentimento que mais marcou o aluno na aula de matemática em situação de aprendizagem. (GUSMÃO, 2009)
}

Entendemos que esta, é uma definição específica, uma vez que a autora se refere exclusivamente às emoções na sala de aula de matemática.

Com respeito a natureza das emoções podemos dizer que estas têm sido objeto de estudo de diversas áreas do conhecimento. No contexto filosófico, foram objeto de reflexão ao longo da história da humanidade. Os filósofos concebiam-nas como elemento essencial da existência e daí o interesse pela natureza e relação das emoções com o cognitivo. Ressaltando o pensamento de Dantzer e do filósofo Wetzel, Lopes (1997) nos informa que elas são consideradas mais como uma atitude que uma conduta reflexiva ou uma simples reação. Nas palavras de Dantzer (apud LOPES, p.15), a emoção pode ser "uma avaliação dos seus próprios estados em relação, eventualmente, com outra pessoa, juiz ou partido”.

Quanto ao estudo das emoções na psicologia, podemos lembrar William James que conforme Damásio (1996) "postulou a existência de um mecanismo básico em que determinados estímulos no meio ambiente excitam, por meio de um mecanismo inflexível e congênito, um padrão específico de reação do corpo". 

EMOÇÕES NA AULA DE MATEMÁTICA

Segundo Lopes (1997, p.19), na psicologia experimental, o organismo é submetido aos constrangimentos do meio envolvente, porém, sem grande capacidade de iniciativa. $\mathrm{Na}$ psicologia cognitiva, o tratamento que o organismo dá às informações dependerá da sua interpretação com base em experiência e expectativa.

Ao atualizar a discussão, têm-se os trabalhos de Goleman (1995), que propõe o conceito de inteligência emocional ou quociente emocional (Q.E.) em paralelo ao de quociente de inteligência (Q.I.). Segundo esse autor, as emoções bem controladas constituemse em fator essencial para desenvolver a inteligência; Gardener (1994) concebe pelo menos sete tipos de inteligências, o que desafia a noção de inteligência única. Das sete inteligências apresentadas, duas apresentam suas origens nos sentimentos, numa gama de afetos e emoções, a saber: a inteligência intrapessoal e a inteligência interpessoal.

No campo das neurociências, existem os estudos de Damásio (1996) que trazem novas informações sobre os mecanismos cerebrais envolvidos na experiência emocional, destacando a importante tarefa das tomadas de decisão, bem como suas consequências para os processos educacionais.

Dito um pouco sobre a natureza das emoções, vamos agora conhecer um pouco sobre suas funções.

Há investigadores que partem do pressuposto de que as emoções são um fenômeno individual e intrapsíquico. Nesse contexto, elas desempenham uma função de adaptação, favorecendo a sobrevivência tanto do homem como da espécie animal; servem de sinal e através da postura, expressão facial, voz e gestos, pode-se acessar aos estados emocionais de uma pessoa. (DANTZER apud LOPES, 1997)

Com Lopes ficamos informados, também, de que há investigadores que vão um pouco mais longe e que as emoções envolvem interações entre o sujeito e o meio. Assim, as emoções desempenham, no contexto social, uma variedade de funções. Essa autora aponta algumas funções sociais fundamentais das emoções: modificar interações individuais de acordo com o que é importante no momento, regular o equilíbrio do poder, como por exemplo, fazendo ameaças ou retaliações, determinar estruturas gerais da interação social, tais como o cuidado com o olhar dos outros (como na emoção de culpa) e representar e motivar a coesão social (tal como na partilha social da emoção). 


\section{PERCEPÇÕES E REAÇÕES DE PROFESSORES E ALUNOS FRENTE ÀS EMOÇÕES NA AULA DE MATEMÁTICA}

A autora ressalta ainda que a forma como as emoções realizam estas funções sociais depende dos diferentes papéis sociais que elas desempenham: Primeiro, o de assegurar a transmissão social das interpretações emocionais dos eventos; Segundo, tendem a levar a um comportamento que influenciam outros; Terceiro, tendem a induzir reações nos outros; Quarto, por serem em parte determinadas socialmente pelas codificações dos eventos, ajudam a mantê-las (codificações) e a definição emocional comum do meio ambiente.

O contexto de significados socialmente partilhados das emoções tem muita importância no processo de ensino e aprendizagem uma vez que, "o sistema professor-alunos é caracterizado por emitir e receber um conjunto de sinais reveladores do seu estado emocional que podem proporcionar ou não um bom ambiente" (LOPES, p.31). Como este ambiente é percebido dependerá de cada um, de acordo com a especificidade, experiências anteriores (conhecimento de mundo), bem como de seu ambiente sócio-econômico-cultural. Dessa forma, lê-se que as emoções

São fatos sociais que continuamente elaboram a rede de papéis sociais e relações. A significância das emoções não existe somente para o sujeito. Existe, justamente, com muita força para o meio ambiente social em que o sujeito está inserido, transmitindo os significados socialmente partilhados" (LOPES, 1997 p.31).

Ao se reportar à matemática, observamos com essa autora o quanto dos nossos alunos não gostam da matemática e estudam simplesmente a matéria para "sobreviver" na sociedade.

Para Damásio (1996), as emoções são necessárias ao ser humano, seja como facilitadora da comunicação, seja como indicadores rápidos e eficientes nas tomadas de decisão. Esse autor afirma-nos que a função atribuída às emoções na criação da racionalidade dispõe de implicações nas questões de educação e também da violência, pois a questão emocional tem se expressado inclusive nos comportamentos agressivos.

Falado brevemente sobre a natureza e função das emoções, adentramos em como elas podem ser percebidas, ou seja, como se expressam.

As emoções não ficam puramente internas, falam através do corpo, aparecem na linguagem corporal. Estudos sobre as expressões faciais revelam o uso de dois paradigmas para reconhecer emoções básicas. Um que se volta para a expressão facial e consiste em 

EMOÇÕES NA AULA DE MATEMÁTICA

inserir os sujeitos em situações que suscitam emoções e outro, que se volta para o reconhecimento das expressões emocionais. (GUSMÃO, 2009; GASCÓN, 2000)

Todavia, ressaltamos que as emoções têm seus termos variados de acordo com cada cultura, segundo seus fatores linguísticos, pois as diferenças culturais, normalmente, interferem sobre as regras de expressão das mesmas. Alguns estudos sobre as expressões faciais apontam como básicas seis emoções: felicidade, medo, desgosto, tristeza, surpresa e cólera; outros, que as emoções básicas são nove: alegria, surpresa, tristeza, cólera, desgosto, desconfiança, medo, vergonha/timidez e culpabilidade. Embora haja variação cultural nas manifestações expressivas, normalmente as consideradas básicas não são difíceis de serem percebidas (GUSMÃO, 2009).

\section{Contribuições no domínio da Educação Matemática}

Em se revendo os aspectos emocionais e sua relação com a aprendizagem de matemática, destacamos os estudos de McLeod (1988, 1989, 1991) e de Chacón (2000) que apresentam como objeto central as variáveis afetivas durante resolução de problema matemático. Entre as variáveis que mais influem no desempenho do aluno diante de problemas propostos têm-se: confiança, ansiedade, frustração e satisfação. Para estes autores, respostas emocionais como essas são fatores importantes na resolução de problemas merecendo, portanto, ocupar uma posição mais central nas preocupações dos investigadores.

Lopes (1997) traz resultados de como os aspectos afetivos-emocionais e, em particular, as emoções e as disposições afetivo-emocionais, juntamente com a atmosfera afetivo-relacional estão entrelaçadas na aprendizagem da matemática através da atividade dos alunos na sala de aula.

Ao estudar alguns dos significados da relação aluno-matemática, a partir de uma abordagem fenomenológica, Chamie (1990) buscou uma resposta à pergunta: "que dificuldades os alunos sentem em relação à Matemática?” (grifo nosso). Na análise final apontou para as seguintes dificuldades: (a) a falta de elo entre o conhecimento matemático que expressa sua linguagem artificial (linguagem teórica, pois o que a autora considera como linguagem natural é a empírica) e o referente matemático (objetos reais dos quais a linguagem artificial fala), ou seja, as idealidades; (b) o modo como a matemática é apresentada aos 


\section{PERCEPÇÕES E REAÇÕES DE PROFESSORES E ALUNOS FRENTE ÀS EMOÇÕES NA AULA DE MATEMÁTICA}

alunos: ciência acabada e formalizada; (c) um preconceito generalizado de que compreender matemática é um privilégio para poucos, conduzindo a resultados negativos do tipo: nãogosto acho-difícil.

Ao estudar os sentimentos construídos pela matemática, os quais chama de evocativos, Fonseca (1991) procurou buscar um sentido para o ensinar matemática, supondo uma "matematicidade" própria do ser humano e apostando no ensino da matemática como "educação da matematicidade". Para ela, matematicidade é: "A disponibilidade, a possibilidade de a pessoa abrir-se e deixar emergir seu senso matemático e traduzi-lo em sentimento, raciocínio, ação ou representação. Esta matematicidade está presente nas mais diversas situações e nos orienta considerações, julgamentos e decisões" (p.50).

A autora procurou olhar para os aspectos afetivos batizados por ela de caráter evocativo da matemática. E ao vislumbrar o caráter evocativo, supõe que este justifica o ensino da matemática, uma vez que as "evocações" favorecem "possibilidades educativas" que podem "provocar uma transformação na nossa maneira de sentir, pensar e sonhar o mundo e a nós mesmos, que nos venha convocar a criar, construir e participar da transformação do mundo, sendo-no-mundo" (p.50 grifo da autora).

$\mathrm{Na}$ tentativa de desvelar os mitos que a sociedade carrega sobre o tema razão e emoção Gusmão (2009), buscou responder as perguntas: Quais as emoções suscitadas no aluno pela percepção do erro em aulas de matemática? Quais as influências dessas emoções na aprendizagem de matemática? Os erros podem se constituir em obstáculos emocionais e influenciar a aprendizagem de matemática? Fazendo uso da História Oral como metodologia do trabalho, a autora enveredou pela narrativa onde mesclou realidade e ficção num diálogo entre dois professores de matemática que trouxeram à luz o referencial teórico sobre razão e emoção fundamentado em muitos investigadores, entre os quais os já aqui mencionados. Participaram de sua pesquisa professores de Matemática que vem revelar que as emoções podem aparecer ajudando a superar ou a criar obstáculos para a aprendizagem de matemática e ainda, que somos razão e emoção e que a convivência entre ambas não é nada pacífica.

Amorim (2017) investigando a atenção que professores dão as emoções de seus alunos em sala de aula, conclui que quanto mais o professor empreende atividades motivadoras com situações de aprendizagem, incentiva o diálogo entre os estudantes e docente e concebe o erro 

EMOÇÕES NA AULA DE MATEMÁTICA

como processo de aprendizagem, melhor será a sua prática educativa no sentido de dar mais espaço para perceber e atender as emoções de seus alunos em sala de aula.

Figueira (2019) estudando a variável afetiva ansiedade e desempenho acadêmico, demostra que o quadro de ansiedade matemática pode ser consequência do contato com atitudes negativas em relação à matemática e com indivíduos com altos níveis de ansiedade nessa disciplina e que o nível de ansiedade matemática de professores de matemática também influencia na ansiedade de alunos e, portanto, essa variável tem grande impacto no desempenho académico de alunos.

Embora alguns estudos reconheçam a presença dos aspectos afetivos/emocionais interferindo na aprendizagem de matemática, as investigações destes aspectos continuam a ser periféricas no domínio da Educação Matemática.

\section{Percurso metodológico}

Nossos dados foram coletados em quatro escolas da educação básica: três da rede particular e uma da rede pública do município de Vitória da Conquista/BA.

Participaram desta pesquisa nove professores de matemática e seus respectivos alunos, das séries finais do ensino fundamental e médio, os quais prontificaram-se a responder os questionários por nós propostos, e tiveram suas perguntas pautadas nos objetivos da pesquisa. Os participantes discorreram livremente diante das perguntas: Você percebe alguma emoção no seu (professor/aluno) durante as aulas de matemática? Na sua percepção quais as emoções que mais ocorrem no seu (professor/aluno) na sala de aula? A seu ver, o que provocam as emoções do seu (professor de matemática/aluno) na sala de aula? Poderia nos dizer como você reage as emoções do seu (professor/aluno)?

Dentro da perspectiva da pesquisa qualitativa, confrontamos os depoimentos, de professores e alunos que, por serem de natureza opinativa, "exprimem a concepção de um indivíduo a respeito de si mesmo, de uma situação ou de outrem, envolvendo suas crenças, sentimentos, valores, opiniões, etc.” LUNA (1998). Os depoimentos revelaram também, a forma como percebem e reagem às emoções durante as aulas de matemática; as emoções mais facilmente reconhecidas por eles e ainda, o que as provocaram. 


\section{PERCEPÇÕES E REAÇÕES DE PROFESSORES E ALUNOS FRENTE ÀS EMOÇÕES NA AULA DE MATEMÁTICA}

\section{Resultados e Discussões}

Ao confrontarmos os depoimentos, elegemos quatro eixos temáticos para as nossas discussões: (1) percepção das emoções; (2) o que provocam as emoções de professores e alunos; (3) emoções mais facilmente reconhecidas; (4) como professores e alunos reagem às emoções.

\subsection{Percepção das emoções}

Nos depoimentos constatamos que nem sempre professores e alunos percebem as emoções uns dos outros na sala de aula de matemática. Nas respostas dos que disseram perceber, notamos um desconhecimento sobre o que venha a ser emoção, dados os termos usados: "percebo a emoção no carinho, afeto, amor, amizade...", o que revela uma imprecisa interseção entre os termos afeto e emoção. Nesse sentido, torna-se preciso estabelecer suas diferenças. "O termo afeto é utilizado, amplamente e com frequência, para cobrir uma variedade de experiências das quais emoções e preferências fazem parte" (GUSMÃO, 2009). Segundo essa autora, enquanto o termo emoção costuma ser utilizado para experiências breves e intensas, o termo afeto é usado para experiências menos intensas e prolongadas.

Verificamos diferentes situações nas quais professores e alunos percebem as emoções uns dos outros. "Percebo muitas vezes quando erramos alguma questão. Ela [a professora] fica decepcionada e triste porque ela quer realmente passar tudo que sabe para nós."

Na verdade, as emoções variam entre pessoas e situações. Um dos fatores responsáveis pela variação é a intensidade com que ela se manifesta. Muitas vezes são percebidas por meio das expressões faciais, por exemplo, um sorriso, como nos fala um aluno em outro depoimento: “Quando o professor está sorridente ensina bem. Quando está zangado erra nos cálculos e troca muitas coisas".

De um modo geral, os professores reconhecem que as emoções dos seus alunos costumam se manifestar mais comumente através do desprezo que o aluno demonstra pelo professor, pelo prazer que demonstram pela aprendizagem, nos momentos de erros e acertos e na indisciplina. Já os alunos disseram que as emoções dos seus professores costumam aparecer nos momentos em que o professor compartilha com prazer o conhecimento que 

EMOÇÕES NA AULA DE MATEMÁTICA

possui, quando motiva a aula, quando se mostra "frio" e indiferente às conquistas dos seus alunos e quando dão chiliques e broncas quando estão irritados.

\subsection{Emoções facilmente reconhecidas}

Em se tratando de emoções, nota-se na sala de aula um jogo dualístico, através do qual há o reconhecimento de uma emoção em detrimento de outra.

Como era de se esperar, as emoções (respostas emocionais) foram dicotomizadas pelos professores em: satisfação e frustração (nos momentos de acertos e erros), também, alegrias e tristezas, medo e confiança, calma e nervosismo.

Assim como ocorreu com os professores, as emoções percebidas pelos alunos também foram dicotomizadas em: satisfação e frustração (quando correspondem ou não as expectativas do professor) em outras situações alegrias e tristezas (por exemplo nos resultados da avaliação).

Aprendemos a rotular as emoções dicotomicamente como alegres/tristes, boas/más, positivas/negativas, agradáveis/desagradáveis. Também dicotomizamos atividade física e atividade mental, dor e prazer, Ciências Exatas e Ciências Humanas, objetivo e subjetivo, concreto e abstrato, razão e emoção. Tais dicotomias invadem nosso modo de pensar, de agir e de sentir e, como consequência, a vida é interpretada por fragmentos do conhecimento. (WEIL, 1993; SARMENTO, 1995; CAPRA, 1982; DAMÁSIO, 1996)

Nesse contexto, uma questão se apresenta: Qual emoção é a melhor?

Gusmão (2009) responde a esta questão nos dizendo que não se trata de melhor ou pior. A dicotomia existe e está dentro de cada um de nós. Vivemos com emoções agradáveis e desagradáveis. Alunos e professores ficam tristes e alegres. A convivência com as dicotomias, em particular razão e emoção, não é nada pacífica, pelo contrário, é conflituosa. Entretanto, aprendemos com elas.

\subsection{0 que provocam as emoções}

São muitos os fatores que provocam as emoções de alunos e professores na aula de matemática. Do ponto de vista do professor, fatores como: relacionamento entre professor- 


\section{PERCEPÇÕES E REAÇÕES DE PROFESSORES E ALUNOS FRENTE ÀS EMOÇÕES NA AULA DE MATEMÁTICA}

aluno e aluno/aluno, atividades voltadas para o interesse do aluno, novidades, problemas pessoais e familiares, aprovação e reprovação são provocadores de emoções nos alunos. Do ponto de vista do aluno, o que provocam as emoções no seu professor são: problemas financeiros, indisciplina, problemas sexuais, a própria profissão, ter que repetir a explicação de um conteúdo, as perguntas do aluno, desrespeito, notas baixas, expectativas frustradas, carga horária excessiva de trabalho, atividades paralelas (ter que "fazer bicos"), o prazer de ensinar, desempenho dos alunos, traços de personalidade do professor (como arrogância, grosseria, autoritarismo e nervosismo) bem como outras atitudes dos alunos em sala de aula (como exemplo, "peitar" o professor).

Professores e alunos parecem ter consciência dos motivos desencadeadores das emoções. Entretanto, somente estar consciente não basta. A experiência tem se mostrado insuficiente. Professores e alunos sentem dificuldades em lidar com os estados emocionais, devidas, em parte, a uma herança cultural questionável sobre as emoções, já apresentada; em parte decorrentes de um desconhecimento sobre os processos emocionais e, talvez em maior parte, devidas aos mecanismos de resistência ao reconhecimento e aceitação das emoções tidas como impróprias ou desagradáveis socialmente.

\subsection{Como professores e alunos reagem às emoções na sala de aula}

Muitas são as situações indicadoras de estados emocionais na sala de aula. Entretanto, saber lidar com elas tem sido um grande desafio de professores e alunos.

Poucos foram os alunos que disseram reagir às emoções de seus professores. Encarando-as normalmente, prestando atenção à aula, demonstrando-se interessado, retribuindo da mesma forma como o professor reage as suas emoções, foram algumas das respostas a nós apresentadas.

Nos depoimentos, os professores disseram reagir às emoções da seguinte forma: procurando reforçar aquelas que são positivas e reverter ou não aceitar as que são negativas; considerando-as como prioritárias no processo ensino-aprendizagem; tentando romper com os mitos em torno da matemática e levando as emoções na "esportiva".

Professores e alunos assumem ter dificuldades em lidar com situações que indicam estados emocionais, principalmente as que indicam raiva e tristeza. Muitas das reações tidas 

EMOÇÕES NA AULA DE MATEMÁTICA

por eles levam a acentuar o quadro dicotômico que já existe. Na sala de aula então, com um número grande de alunos, torna-se mais difícil dar conta delas. Também o caráter vulnerável e imprevisível com que as emoções se apresentam, é fator que contribui para acentuar o quadro dessas dificuldades.

\section{CONCLUSÕES}

A reflexão aqui empreendida, embora sucinta, faz parte das preocupações que alguns investigadores têm na tentativa de incorporar efetivamente a discussão dos aspectos emocionais no desenvolvimento do currículo e na formação de professores. Portanto, esta não é mais que uma contribuição a uma abordagem que começa a ganhar espaço e importância nas investigações em Educação Matemática e na educação em geral.

Com esta pesquisa buscamos informações sobre: como professores e alunos de matemática percebem e reagem às emoções em sala de aula; como fatores de traços de personalidades provocam as emoções e como essas variáveis afetam o processo de ensinoaprendizagem.

De um modo geral, esta pesquisa aponta a necessidade de discussão dos aspectos afetivos/emocionais dentro do currículo e na formação de professor. Não se trata, como vimos, de reconhecer uma emoção em detrimento da outra. Também não basta achá-las prioritárias para que o processo ensino aprendizagem aconteça. É preciso que professores e alunos conheçam mais a respeito do sistema emocional. Saibam da sua natureza, função, como se manifestam, para daí compreender suas implicações nos processos de raciocínio. Uma educação que descarta a emoção, ao estabelecer uma linha demarcando a emoção e a razão, não contribui para uma aprendizagem efetiva.

Os depoentes-participantes desta pesquisa apontaram como provocadoras de emoções variáveis do tipo: desajustes familiares, indisciplina, indiferença, problemas financeiros, expectativas satisfeitas ou frustradas, erros e acertos. A grande dificuldade foi lidar com as emoções daí decorrentes. Somando-se a esses fatores da sala de aula, diremos ainda que, outras variáveis de ordem socioeconômica e cultural como o conflito de gerações, as diferenças culturais, desemprego, droga, violência são acontecimentos que não escapam da 


\section{PERCEPÇÕES E REAÇÕES DE PROFESSORES E ALUNOS FRENTE Às EMOÇÕES NA AULA DE MATEMÁTICA}

esfera educacional e, portanto, da Educação Matemática. Pesquisas, como as aqui apontadas, têm mostrado que esses acontecimentos acabam por influenciar no processo de aprendizagem de matemática.

Assim, a ausência de uma educação que aborde a emoção na aula pode trazer sérios prejuízos para a ação pedagógica, e suas consequências atingir não só o professor, como também o aluno. (ALMEIDA, 1999; GUSMÃO, 2009; GASCÓN, 2000).

\section{REFERÊNCIAS}

AMORIM, L. C. A atenção dada às emoções na sala de aula pelo professor de matemática: contribuições dos critérios de idoneidade didática. Jequié, $\mathrm{Ba}, 2017$. Dissertação de Mestrado, Programa de Pós-Graduação em Educação Científica e Formação de Professores- UESB.

ALMEIDA, A. R. S. A emoção na sala de aula. Campinas, SP: Papirus, 1999.

CAPRA, F. O ponto de mutação. 14. ed. Tradução Álvaro Cabral. São Paulo: Cartaz, 1980.

CHAMIE, L. M. S. A Relação Aluno-Matemática: alguns de seus significados. Rio Claro, SP, 1990. Dissertação de Mestrado - UNESP.

DAMÁSIO, A. R. O Erro de Descartes: emoção, razão e cérebro humano. Tradução portuguesa Dora Vicente e Georgina Segurado. 4 ed. São Paulo: Companhia das Letras, 1996. Título original: Descartes'error: emotion, reason and the human brain.

FIGUEIRA, P. V. S. T. Ansiedade matemática em crianças com baixo desempenho em aritmética: memória de trabalho, controle inibitório, e efeitos da ansiedade matemática de pais e professores. Vitória da Conquista, Ba, 2019. Dissertação de Mestrado, Programa de Pós-Graduação em Ensino- UESB.

FONSECA, Ma . C. F. R. O evocativo na sala de aula: uma possibilidade educativa. Rio Claro, SP, 1991. Dissertação de Mestrado - UNESP.

GARDNER, H. Estruturas da Mente: A teoria das inteligências múltiplas. Tradução Sandra Costa. Porto Alegre: Artes Médicas Sul, 1994.

GASCÓN. I. Mª G. Matemática Emocional. Madrid: Narcea, S.A. 2000. 

EMOÇÕES NA AULA DE MATEMÁTICA

GOLEMAN, D. Inteligência emocional: A teoria que redefine o que é ser inteligente. Revisão da Tradução: Ana Amélia Schuquer. 54 ed. Rio de Janeiro: Objetiva, 1995. Título Original: Emotional Intelligence.

GUSMÃO, T. C. R. S., EMERIQUE, P. S. Do erro construtivo ao erro epistemológico: um espaço para as emoções. Bolema, Rio Claro, (n.14), (p. 51-65). 2000.

GUSMÃO, T. C. R. S. Em cartaz: razão e emoção na sala de aula. Edições UESB, Vitória da Conquista, Ba, 2009.

LOPES, I. Ma. F. do C. Aspectos afectivos da actividade matemática escolar dos alunos. Lisboa, 1997. Dissertação de Mestrado - Departamento de Educação da Faculdade de Ciências - Universidade de Lisboa.

LUNA, S. V. Planejamento de pesquisa: Uma introdução. São Paulo: EDUC, 1998.

McLEOD, D. B., ADAMS, V. M. Affect and mathematical problem solving: A new perspective. Editors with 16 illustrations. Springer - Verlag New York, London, Paris, Tohyo, Berlin, Heidelberg. 1989.

Affective issues in mathematical problem solving: Some theoretical considerations. Washington State University. (Journal for Research Mathematics Education, 1988, vol.19, no. 2, 134-141).

SARMENTO, M. S. Interdisciplinaridade: Diálogo e sobrevivência. Jequie, Bahia: Universidade Estadual do Sudoeste da Bahia, [ca. 1995]. (Mimeogr.)

SYLWESTER, R. How Emotions Affect Learning. Educational Leadership, University of Oregon, Eugene, 1994, v. 52, n. 2.

WEIL, P. et. al. Rumo a nova transdisciplinaridade: Sistemas abertos do conhecimento. São Paulo: Summus, 1993. 


\section{Sobre os autores}

Tânia Cristina Rocha Silva Gusmão é Doutora em Didática da Matemática pela Universidade de Santiago de Compostela (USC). Professora na Universidade Estadual do Sudoeste da Bahia (UESB), no Programa de PósGraduação em Educação Científica e Formação de Professores e no Programa de Pós-Graduação em Ensino, ambos na UESB. Coordenadora do Grupo de Estudos e Pesquisas Museu Pedagógico: Didática das Ciências Experimentais e da Matemática (GDICEM/UESB). Endereço eletrônico: professorataniagusmao@gmail.com

Mariluce Cidade França Doria é Mestre em Tecnologias Aplicadas à Bioenergia pela Faculdade de Tecnologia e Ciências de Salvador - FTC (2017). Possui Especialização em Matemática pela Universidade Estadual do Sudoeste da Bahia UESB (2000) e Especialização em Engenharia e Segurança do Trabalho pela Faculdade de Tecnologia e Ciências - FTC (2012). Graduada em Engenharia Civil pela Universidade Católica do Salvador - UCSal (1984). Tem experiência nas áreas de Engenharia Civil e na área de Educação e Educação Matemática. É membro pesquisadora do grupo de pesquisa Museu Pedagógico: Didática das Ciências Experimentais e da Matemática. Atua principalmente nos temas: cognição, metacognição, afetividade, resolução de problemas e avaliação. É professora na rede particular de ensino básico e superior.

Endereço eletrônico: marilucedoria@gmail.com

José Eduardo Rocha Silva é Mestre em Ensino pela Universidade Estadual do Sudoeste da Bahia - UESB, na Linha de Pesquisa: Ensino e Aprendizagem de Ciências Exatas, Experimentais e Naturais (2018); Psicanalista Clínico pela CORPO/CESBAN (2005). Pós-graduado em Psicologia Clínica e Psicanálise pela UNIARA. Graduado em Administração pela Faculdade Juvêncio Terra (2007). Membro do Grupo de Estudos e Pesquisas Museu Pedagógico: Didática das Ciências Experimentais e da Matemática (GDICEM), atuando na linha de pesquisa: Processos Cognitivos, Afetivos, Metacognitivos, Resolução de Problemas e Tecnologias Digitais no Ensino. Endereço eletrônico: joseeduardorocha@gmail.com 